\title{
Information technologies for the study of the planned and profile model of the flux creep in the transit channel
}

\author{
Elguja Khetsuriani ${ }^{1,2^{*}}$, Teona Khetsuriani $^{1}$, and Timur Khetsuriani ${ }^{2,3}$ \\ ${ }^{1}$ M. I. Platov South Russian State Polytechnic University (NPI), 346400 Novocherkassk, Russia \\ ${ }^{2}$ Don State Technical University, 344000, Rostov-on-Don, Russia \\ ${ }^{3}$ Rostov State Medical University, 344022 Rostov-on-Don, Russia
}

\begin{abstract}
The article presents the inlet chamber computer models for the Beloyarskyin take structure: a computer model of the depth distribution and a computer model of the water level distribution for determining the hydrodynamic structure of the flux creep in the transit channel. To build a computer model, the depth survey of the inlet chamber was used during hydro meteorological surveys. The water level at the survey time is 15.30 $\mathrm{m}$. The construction of a depth distribution computer model in the inlet chamber at the intake structure for the water supply of the Beloyarsky city was carried out by the finite element method on a personal computer in the Multiphysics software product. The uneven distribution of average velocities on the verticals, both along the channel width and length, is explained by the significant expansion of the inlet chamber in the intermediate sections $2-2,3-3,4-4,5-5$ in relation to the input $1-1$ and output sections. Deepening the channel in the entrance section 1-1 by an average of $1.3-1.5 \mathrm{~m}$ will increase its flow rate to $10,2 \mathrm{~m} 3 / \mathrm{s}$ or 10 times with an increase in the average speeds on the verticals by 2.0-2.5 times. Such an increase in the flow rate in the input section will lead to an increase in the average speeds in other sections 2-2, 3-3, etc. Hence, the passage of increased flow through the transit channel after clearing a number of shallow areas will create better conditions for preventing algae spread.
\end{abstract}

\section{Computer model of depth distribution}

To build a computer model, a survey of the intake structure depths during hydro meteorological surveys was used. Water level at the time of the survey is $15.30 \mathrm{~m}$.

The construction of a computer model of the depths' distribution in the inlet chamber at the inlet chamber for the water supply of the Beloyarsky city was carried out by the finite element method on a personal computer in the Multiphysics software product. The sequence of computer simulation includes the following steps:

1. At the first stage, we set the simulation mode for the Laplace equation on the plane:

\footnotetext{
*Corresponding author: goodga@mail.ru
} 


$$
\Delta h=\frac{\partial^{2} h}{\partial x^{2}}+\frac{\partial^{2} h}{\partial y^{2}}=0
$$

where $h$ is water flow depth; $x$ is an abscissa; $y$ defines ordinate; $\Delta$ is a Laplacian operator.

2. Then we build the geometry of the computational domain, shown in Figure 1 and including 337 reference points, 12 transverse profiles, as well as a longitudinal average profile

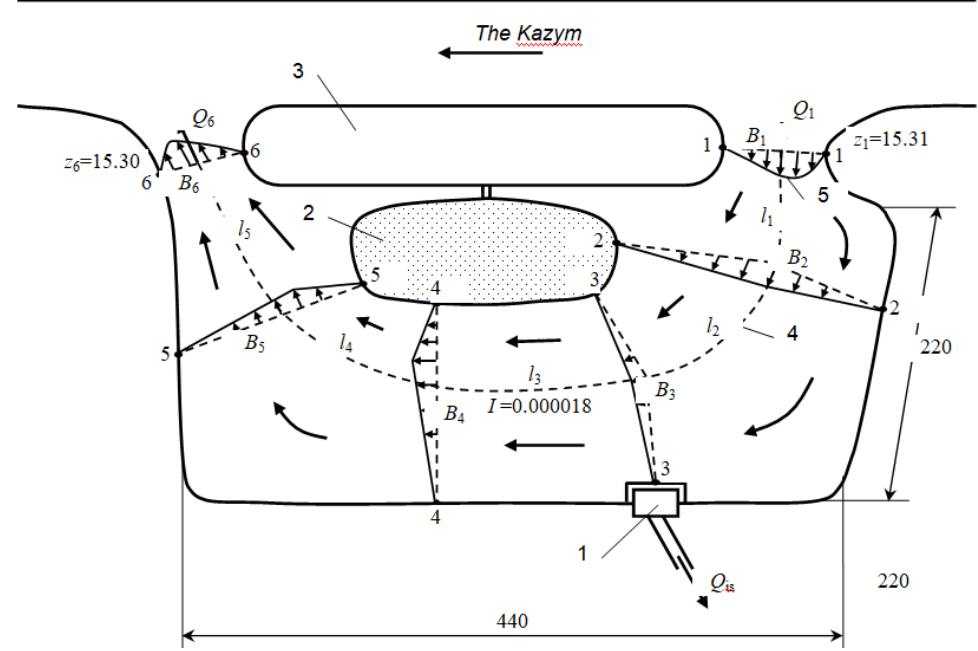

Fig. 1.The geometry of the computational domain

3. Next, we set the Dirichlet boundary conditions shown in Figure 1:

- in the inlet flow section 1-1 $h=h_{1-1}(x, y)$;

- in the outlet section of the flow 11-11 $h=h_{11-11}(x, y)$;

- in the intermediate section of the flow 3-3 $h=h_{3-3}(x, y)$;

- in the intermediate section of the flow 6-6 $h=h_{6-6}(x, y)$;

- in the intermediate section of the flow 8-8 $h=h_{8-8}(x, y)$;

- in the intermediate section of the flow $9^{\prime}-9^{\prime} h=h_{9^{\prime}-9^{\prime}}(x, y)$;

- in the longitudinal mean flow profile $1^{\prime}-11^{\prime} h=h_{1^{\prime}-11^{\prime}}(x, y)$;

- on the remaining external borders (off the coast and on the bridge between the islands) $h=0$, where $h_{1-1}(x, y), \quad h_{11-11}(x, y), \quad h_{3-3}(x, y), \quad h_{6-6}(x, y), \quad h_{8-8}(x, y), \quad h_{9^{\prime}-9^{\prime}}(x, y)$, $h_{1^{\prime}-11^{\prime}}(x, y)$ - the depth distribution in the sections 1-1, 11-11, 3-3, 6-6, 8-8, 9' - 9', $1^{\prime}-11^{\prime}$.

On the remaining internal boundaries (in intermediate sections 2-2, 4-4, 5-5, 7-7, 9-9, 10-10), we set the boundary conditions for the desired function normal derivatives' equality:

$$
\frac{\partial h^{+}}{\partial n}=\frac{\partial h^{-}}{\partial n}
$$

where $\frac{\partial h^{+}}{\partial n}, \frac{\partial h^{-}}{\partial n}$ are the derivatives of the depth distribution along the normal (from the side of the input stream and output stream, respectively). 
4. We build the finite element mesh, shown in Figure 2. 9598 finite elements, representing triangles on the plane, were built.

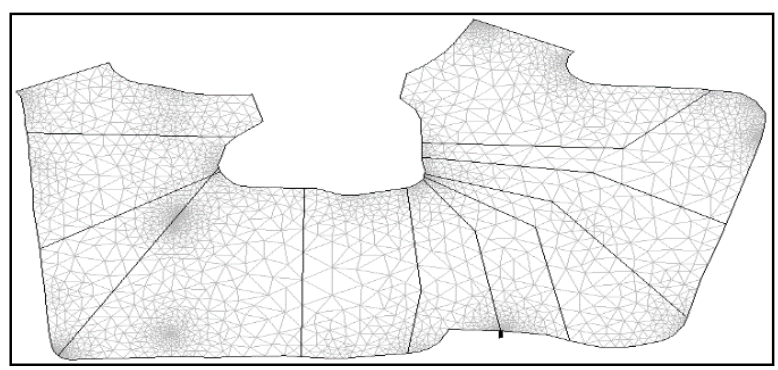

Fig. 2. The finite element mesh in the computer model of the water levels distribution

5. We calculate the depths distribution in the computational domain using the finite element method. The calculation took 0.812 seconds and included 19655 degrees of freedom (or computational domain nodes).

6. We configure the results' output, after which the results of modeling the distribution of depths in the computational domain were obtained. The color distribution of depths is shown in Figure 3.

7. The model is saved in a file on disk, and the graphic representation of the initial data and results is transferred to a text document in the form of bitmaps.

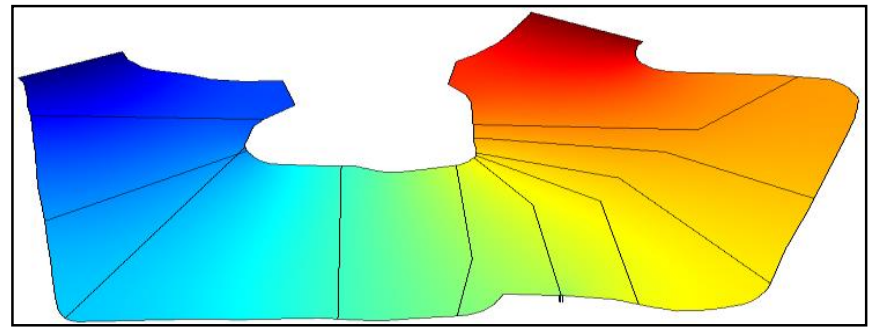

Fig. 3. Color distribution of levels in the calculated area of the water levels distribution computer model

The three-dimensional distribution of depths is shown in Figure 5 (respectively from the front view and the rear view).
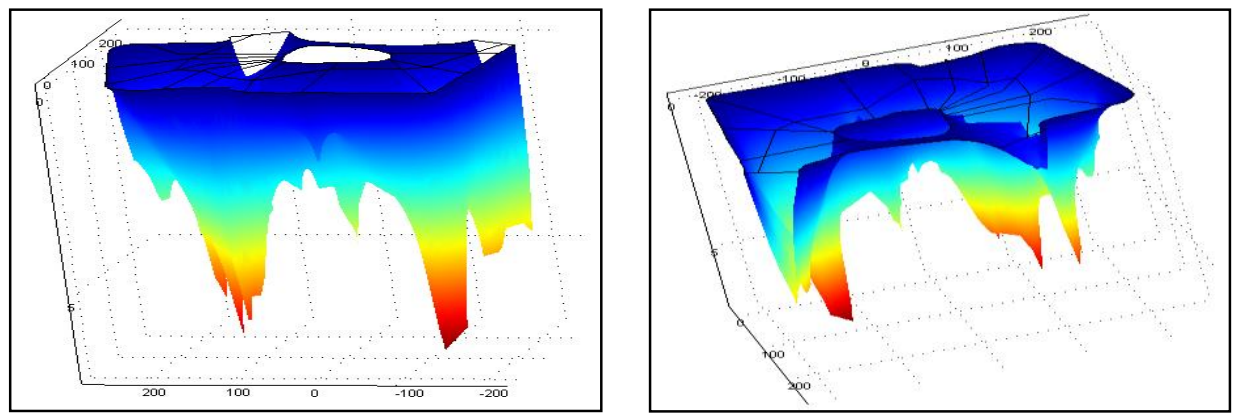

Fig. 4. Three-dimensional flow depth in the computational domain of a computer model water depth distribution: a) from the front view; b) from the rear view

The construction of the water levels distribution computer model is carried out in a similar way to a computer model of the depths' distribution. We also save the model in a 
file on disk, and transfer the graphic representation of the initial data and results to a text document in the form of bitmaps

\section{Hydrodynamic model of the flow in the transit channel}

The hydrodynamic model of the intake structure inlet chamber of the city of Beloyarsky is a backwater with low flow rates (see Figure 1)

Consumption according to the performed hydraulic calculations in the section $1-1$ at water level $z_{1}=15.31 \mathrm{~m} Q_{1}=6.24 \mathrm{~m}^{3} / \mathrm{s}$, in section $6-6-Q_{1}=6.07 \mathrm{~m}^{3} / \mathrm{s}$ (taking into account the water supply to the intake structure $Q_{\text {is }}=0.17 \mathrm{~m}^{3} / \mathrm{s}$ ).

Inlet chamber flow rate in the section 1-1 at the minimum design water level of a given provision $P=90 \% z_{1}=14.69 \mathrm{~m}$, which corresponds to the inlet chamber of category II according to BC 31.13330 .20 [10], is significantly decreased to the value $Q_{1}=1.07 \mathrm{~m}^{3} / \mathrm{s}$ vs $Q_{1}=6.24 \mathrm{~m}^{3} / \mathrm{s}$ at $z_{1}=15.30 \mathrm{~m}$. Average depth in this section at water level $z_{1}=15.31 \mathrm{~m}$ is $h_{\mathrm{av}_{1}}=0.68 \mathrm{~m}$, and the maximum $h_{\max }=1.25 \mathrm{~m}$, and at the minimum water level $z_{1}=14.55 \mathrm{~m}$ the average depth will be $h_{\mathrm{av}_{1}}=0.23 \mathrm{~m}$, maximum depth $-h_{\max }=0.49 \mathrm{~m}$.

The average velocities in the living section 1-1 change similarly: at $z_{1}=15.31 \mathrm{~m}-$ $v_{1}=0.127 \mathrm{~m} / \mathrm{s}$, at $z_{1}=14.55 \mathrm{~m}-v_{1}=0.057 \mathrm{~m} / \mathrm{s}$. In this case, the average velocities on verticals in the hydrodynamic model change significantly along the flow width: for the section $1-1$ at $z_{1}=15.31 \mathrm{~m}-$ from 0.075 up to $0.197 \mathrm{~m} / \mathrm{s}$, shown in Figure 4.3 ; at $z_{1}=14.55 \mathrm{~m}-$ from 0.020 up to $0.105 \mathrm{~m} / \mathrm{s}$; at $\mathrm{z}_{1}=14.69 \mathrm{~m}-$ from 0.075 up to $0.146 \mathrm{~m} / \mathrm{s}$, is shown in Figure 4.4. Average speeds on verticals change not only along the width of the section, but also along the length of the channel. So, for $z_{1}=15.31 \mathrm{~m}$ in the section $1-1$, the highest speeds were $0.197 \mathrm{~m} / \mathrm{s}$, in section $2-2-0.0308 \mathrm{~m} / \mathrm{s}$, in section $3-3-0.0253 \mathrm{~m} / \mathrm{s}$, in the section $4-4-0.061 \mathrm{~m} / \mathrm{s}$, in the section $5-5-0.030 \mathrm{~m} / \mathrm{s}$, in the section $6-6-0.066 \mathrm{~m} / \mathrm{s}$, shown in Figure 6.

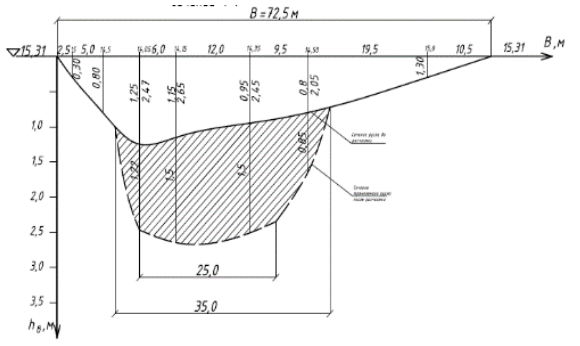

a)

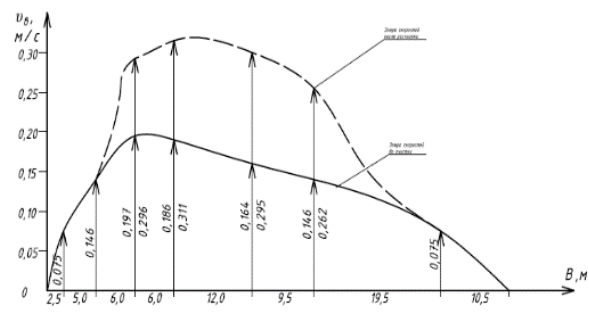

b)

Fig. 6. Cross-section and diagram of average velocities in the section 1-1, at water level of $15.30 \mathrm{~m}$ : a) Transverse profiles and diagrams of average velocities in the inlet chamber (at WL $=15.30 \mathrm{~m}$ ), section 1-1; b) Diagrams of average velocities on verticals along the channel width

Such an uneven distribution of average speeds on the verticals, both in width and along the length of the channel, is explained by the significant expansion of the inlet chamber in the intermediate sections $2-2,3-3,4-4,5-5$ in relation to the inlet 1-1 and outlet sections. In addition, the depths vary along the width and length of the inlet chamber from shallow to deep-water areas (from 0.30 to $5.80 \mathrm{~m}$ ), which is directly reflected in the flow velocities.

Thus, a complex hydrodynamic picture of currents in the intake arises, which is characterized not only by forward, but also by rotational (whirlpool) and reverse currents. 
To determine the calculated level of the inlet chamber (backwater) according to BC 31.13330.2012 [10], art. 8.79, Table 7 for the category II intake structure, the minimum water level is used $P=95 \%$ according to the survey data $z_{P=95 \%}=14.55 \mathrm{~m}$, and the provision of average monthly water discharges according to [10], art. 6.7, Table4 $P=90 \%$ for the II category of the water supply system, for which we use the minimum water level in the intake $z_{P=90 \%}=14.69 \mathrm{~m}$, are presented in Figure 7 .
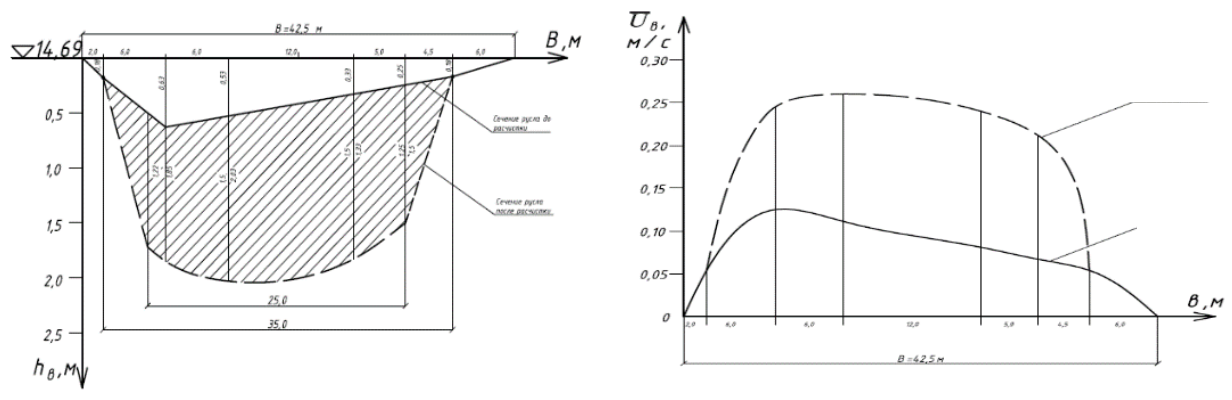

Fig. 7. Transverse Profiles and diagrams of average velocities in the inlet chamber (at WL $90 \%$ $=14.69 \mathrm{~m}$ ). Section 1-1. Diagrams of average velocities on verticals along the channel width

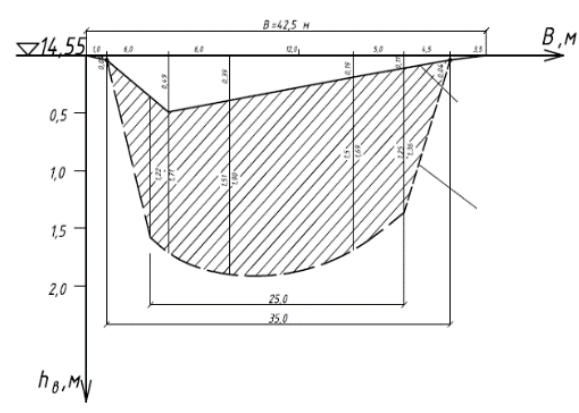

a)

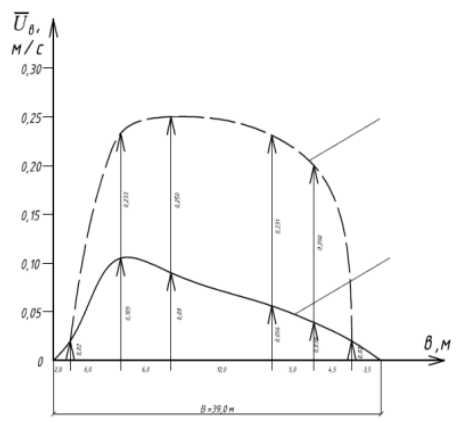

b)

Fig. 8. Transverse profiles and diagrams of average speeds on verticals in section 1-1, at a water level of $14.55 \mathrm{~m}$ : a), Transverse profile (at $\mathrm{WL}_{95 \%}=14.55 \mathrm{~m}$ ). Section 1-1. b) Diagram of average velocities on verticals along the channel width

Based on the analysis of the average velocities on verticals in all sections of the model, on the velocity diagrams shown in Figure 7, at $z_{1}=14.55 \mathrm{~m}$, from those presented in Figure 8 , we can conclude that the average speeds on the vertical 1-1 do not, respectively, exceed $0.105 \mathrm{~m} / \mathrm{s}$, and the average speeds in the living area do not exceed $0.057 \mathrm{~m} / \mathrm{s}$. Even less are the values of speeds on intermediate verticals in sections 2-2, 3-3, 4-4 and 5-5, where the maximum speeds do not exceed 0.059 , respectively; $0.039 ; 0.177 ; 0.058 \mathrm{~m} / \mathrm{s}$. Such low current velocities in the inlet chamber water area cause favorable conditions for algae spread in the summer, especially in the areas with a low intensity of water exchange and in shallow areas with a depth of less than 1.5-2.0 m.

In this regard, it is envisaged to construct a so-called "transit channel" along the line of greatest depths in the cross-sections by deepening shallow-water areas with a depth of more than 2.0-3.0 m and a channel width of $35.0 \mathrm{~m}$, which will increase the average speeds on verticals for 2.5-3.0 times and will create favorable conditions for water exchange and water masses refreshment, both in transit channel and in adjacent areas. 
In this case, particular importance is given to the inlet section 1-1, which is a "bottleneck" in the entire water supply system of the inlet chamber. So, at the minimum water level $z_{1}=14.55 \mathrm{~m}$ the depths in section $1-1$ do not exceed $0.2-0.5 \mathrm{~m}$ at an average depth $h_{\mathrm{av}}=0.23 \mathrm{~m}$. For this reason, the flow rate in the inlet section $Q_{1}$ falls sharply from $6.24 \mathrm{~m}^{3} / \mathrm{s}$ at $z_{1}=15.30 \mathrm{~m}$ up to $0.51 \mathrm{~m}^{3} / \mathrm{s}$ at $z_{1}=14.55 \mathrm{~m}$, i.e., there is a decrease of more than 12 times.

Deepening the channel in the inlet section 1-1 by an average of 1.3-1.5 m will increase its flow up to $10,2 \mathrm{~m}^{3} / \mathrm{s}$ or 10 times with an increase in average speeds on verticals by 2.0 2.5 times. Such an increase in discharge in the inlet section will lead to an increase in average velocities in other sections 2-2, 3-3, etc. Hence, the passage of an increased discharge along the transit channel after clearing a number of shallow-water areas will create better conditions for preventing the development of algae.

\section{Conclusion}

1. To build a computer model of the depth distribution, the survey of the inlet chamber was used during hydro meteorological surveys. Water level at the time of the survey was $15.30 \mathrm{~m}$.

2. For the water levels distribution, it was taken into account that the level in the inlet and outlet sections differs by $1 \mathrm{~cm}$. The water level in the inlet section was taken equal to $15.31 \mathrm{~m}$, and in the outlet section it was taken equal to $15.30 \mathrm{~m}$.

3. The construction of a computer model in the inlet chamber at the intake structure for the water supply of the Beloyarskycity was carried out by the finite element method on a personal computer in the Multiphysics software product using the Laplace equation.

4.The uneven distribution of average speeds on the verticals, both in width and along the length of the channel, is explained by a significant expansion of the inlet chamber in the intermediate sections $2-2,3-3,4-4,5-5$ in relation to the inlet $1-1$ and outlet sections.

5.Deepening the channel in the inlet section 1-1 by an average of 1.3-1.5 m will increase its flow up to $10,2 \mathrm{~m}^{3} / \mathrm{s}$ or 10 times with an increase in average speeds on verticals by 2.0 2.5 times. Such an increase in the inlet section discharge will lead to an increase in average velocities in other sections 2-2, 3-3, etc. Hence, the passage of an increased discharge along the transit channel after clearing a number of shallow-water areas will create better conditions for preventing algae spread.

\section{References}

1. V.L. Bondarenko, A.I.Ylyasov, E.D.Khetsuriani, monograph Scientific and methodological foundations of natural-technical systems in the use of water resources: territories of basin geosystems (Novocherkassk,2019)

2. V.L. Bondarenko, E.A.Semenova, A.V.Aliferov, O.V. Klimenko, Natural and technical systems in the use of water resources: territories of basin geosystems: monograph(NPI, Novocherkassk,2016)

3. V.L.Bondarenko, V.B. Dyachenko, Problems of regional ecology 2, 86-92 (2005)

4. M.I. Budyko, O.A. Drozdov, About moisture turnover in a limited land area. Questions of hydrometeorological efficiency of field protection afforestation (Gidrometeoizdat, L., 1950)

5. V.A. Volosukhin, V.L. Bondarenko, Building systems for the protection of water resources using the structures from fabric materials: monograph (Colorit, Novocherkassk, 2008) 
6. K.S. Losev, Environmental problems and prospects for sustainable development of Russia in the XXI century (Kosmosinform, Moscow, 2001)

7. A.M. Chernyaeva, River basins (Publishing house Agroecology, Yekaterinburg, 1999)

8. E.D. Khetsuriani, V.P. Kostyukov, E.G. Ugrovatova, Hydrological research on the river DoninAleksandrovsky WWS Water intake facilities. Procedia techniques 150 (2nd International Conference on Industrial Engineering, ICIE 2016). May 19 2016, Chelyabinsk, Russia (2016)

9. E.D. Khetsuriani, T.E. Khetsuriani, Measures will be taken to combat the eutrophication of water bodies priority tasks and strategies for the development of agricultural science, Sat. science tr. (international Scientific practical Conference FTSNiO EVENSIS) May 25, 2016, Tolyatti, Russia (2016)

10. E.D. Khetsuriani, L.N. Fesenko, A.N. Bogachev, M.M. Mordvinuev, G.N. Puras, A. Yu. Dushenko, R.S. Bechvaya, A.V. Pelcher, Engineering Journal of Don 4 (2015)

11. E.D. Khetsuriani, V.P. Kostyukov, T.E. Khetsuriani, IOP Conference Series: Materials Science and Engineering 262 (2017)

12. E.D. Khetsuriani, V.L. Bondarenko, N.A. Polyansky, IOP Conference Series: Materials Science and Engineering 262 (2018)

13. E.D. Khetsuriani, V.L. Bondarenko, A.I. Ylyasov, E.A. Semenova, The results of the research on the pipelines protection from Zebra mussle on the water intake technological complexes of multi-purpose water supply systems for urban farms, IOP Conference Series: Materials Science and Engineering698, 055041 (International Scientific Conference "Construction and Architecture: Theory and Practice of Innovative Development") 1-5 October 2019, Kislovodsk, Russia, (2019) https://iopscience.iop.org/article/10.1088/1757-899X/698/5/055041/pdf

14. E.D. Khetsuriani, V.L. Bondarenko, A.I. Ylyasov, E.A. Semenova, Lightweight constructions in technical water supply systems of thermal and nuclear power plants, IOP Conference Series: Materials Science and Engineering 698, 055042 (2019). International Scientific Conference "Construction and Architecture: Theory and Practice of Innovative Development" 1-5 October 2019, Kislovodsk, Russia https://iopscience.iop.org/article/10.1088/1757-899X/698/5/055042/pdf

15. E.D. Khetsuriani, V.L. Bondarenko, A.I. Ylyasov, E.A. Semenova, Innovative design solutions to ensure the environmental safety in the existing water intake technological complexes of water systems for urban farms, IOP Conference Series: Materials Science and Engineering 698, 055040 (2019). International Scientific Conference "Construction and Architecture: Theory and Practice of Innovative Development" 1-5 October 2019, Kislovodsk, Russia https://iopscience.iop.org/article/10.1088/1757899X/698/5/055040/pdf

16. E.D. Khetsuriani, V.L. Bondarenko, A.I. Ylyasov, E.A. Semenova, Development of protective measures providing environmental safety in areas affected by water-intake constructions of urban households, IOP Conference Series: Materials Science and Engineering 698, 077053 (2019). International Scientific Conference "Construction and Architecture: Theory and Practice of Innovative Development 1-5 October 2019, Kislovodsk, Russia $\quad$ https://iopscience.iop.org/article/10.1088/1757$\underline{899 X / 698 / 7 / 077053 / p d f}$

17. E.D. Khetsuriani, V.L. Bondarenko, A.I. Ylyasov, Scientific and methodological foundations of environmental safety at water intake technological complexes of multipurpose water supply systems: monograph (Platov South-Russian State Polytechnic University (NPI), Novocherkassk, 2020) 